\title{
Comparative Study on Knowledge Transfer Among Different Networks: a Social Capital Perspective
}

\author{
LIU Shouxian \\ China Center for Industrial Security Research, Beijing Jiaotong University, Beijing, China, 100044 \\ School of Economics and Management, Beijing Institute of Graphic Communication, Beijing, China, 102600 \\ Email: shouxianliu@163.com
}

\begin{abstract}
This paper examines how social capital dimensions of networks affect the transfer of knowledge between network members. There are different characteristics of social capital among three network types: MNCs, strategic alliances and industrial clusters. Based on comparing dimension of social capital among three network types, we links structural, cognitive, and relational dimensions for the three network types with knowledge transfer between network members. At last, using a social capital framework, this paper compares the conditions that promoting knowledge transfer for the different network types.
\end{abstract}

Keywords-network; knowledge transfer; social capital

\section{Introduction}

Recent years, the focus of research on business strategy is from atomic viewpoints to the network viewpoints. And social capital theory provides a new prospect for business strategy. The mode of open innovation and social capital requires knowledge stock of corporate, that is not completely exploited, more thick through new mode such as sharing in knowledge assets, cooperating with external partner and so on.

Researchers recognize that knowledge flow is an entrepreneurial process of learning to acquire and exploit new knowledge and market opportunity ${ }^{[1]}$ and that knowledge is a source of sustainable competitive advantage. Yupeng(2006) examines the mechanism of knowledge transfer within multinational corporate ${ }^{[2]}$. And Wucuihua (2008) indicates that corporate social capital has an positive effect on performance of knowledge transfer moderated by opportunity, motive and capacity variables ${ }^{[3]}$. With perspective of structural and relational dimension of network, Zhang zhiyong et al.(2007) analyzes the influence on knowledge transfer by characteristics of network. They also differentiate features of knowledge transfer between multinational corporate and industrial cluster ${ }^{[4]}$.

Thus, the disparity of knowledge influenced by social capital among different networks is not examined, and it is valuable how to promote knowledge transfer between firms in different networks, such as MNCs, strategic alliances, and industrial clusters.

Based on three dimensions of social capital, this research explores how dimensions of social capital put effect on knowledge transfer between firms in network. The study is implicational to acquire valuable knowledge through relation network and to erect innovative network.

\section{Three Types of Network}

This definition of networks includes a wide range of forms, including multinational corporate(MNC), strategic alliances, franchises, RandD consortia, buyer-supplier relationships, business groups, trade associations, government-sponsored technology programs, and so on. This comparative study focuses on three network types, that is, MNCs, strategic alliances and industrial clusters.

\section{A Multinational Corporate}

In international business research, MNC is commonly conceptualized as a network of units. In this network, units have strategic mandates and thus access and transfer knowledge from different positions (Ghoshal and Bartlett,1990) ${ }^{[5]}$. Although their network positions differ, the corporate embeddedness of organizational units in this network provides a basic social context which is common for all units.

\section{B Strategic Alliance}

A strategic alliance is a group of firms entering into voluntary arrangements that involve exchange, sharing, or co-development of products, technologies, or services (Gulati,1998) ${ }^{[6]}$. Strategic alliance can be formed by firms located in different positions or in the same position of the value chain (Inkpen and Tsang,2004) ${ }^{[7]}$.

\section{Industrial Cluster}

Cluster, a type of network organization, is proved effectively to extend firms' ambits and promoting industries' competitive advantage which origins in co-ordination effect resulting from interaction among actors of cluster. And the co-ordination effect is not inherent, and its effect must rely on two conditions: cluster network and perfect industrial cluster governance. Consequently, perfect industrial cluster governance is inevitable so as to strengthen cluster co-ordination and maintain cluster competitive advantages.

\section{Network Types and Knowledge Transfer}

Knowledge transfer is a process that network member is influenced by experience belong to other members of network. In a growing body of research, scholars argue that organizations able to transfer knowledge effectively from one organizational unit to another are more productive than organizations that are less capable of knowledge transfer 
(Hansen,2002) ${ }^{[8]}$. Especially, novel knowledge from outside the firm is vital to change and organizational improvement.

"The primary reason why MNCs exist is because of their ability to transfer and exploit knowledge more effectively and efficiently in the intra-corporate context than through external market mechanisms"(Gupta and Govindarajan,2000) ${ }^{[9]}$. MNC's internal network is composed of core nude integrating information of products, functions and divisions, and some subsidiaries nudes which perform special strategic function. And there is mass knowledge transfer between parent and subsidiaries and between subsidiaries of MNC.

The previous literature provides a number of statements about factors influencing the extent of inter-firm knowledge transfer in alliances. Inkpen and Tsang (2005) argues that the opportunities for inter-firm transfer of capabilities afforded by different alliance structures influences the choice among them, since equity-based joint ventures are more effective vehicles for the transfer of tacit knowledge between the partners: 'Other forms of transfer, such as through licensing, are ruled out because the very knowledge that is being transferred is organizationally embedded ${ }^{[10]}$.

In their research on evolution of industrial cluster, $\mathrm{Wu}$ and Guo(2010) indicates that extension of innovation and RandD network is dynamics and characteristics in high stage of industrial cluster's development ${ }^{[11]}$. Firms in cluster have lager quantity of opportunities to reach knowledge resources and core knowledge is still implicit. While, geographic proximity originated from cluster contributes to knowledge flow and technological communication between firms.

\section{Social Capital and Dimensions}

In line with social capital theory, researchers argue that social relationships are key sources of resources and learning (Nahapiet and Ghoshal,1998;Tsai and Ghoshal,1998) ${ }^{[1][12]}$. In explaining organizational learning and knowledge transfer, social capital theory gives an emphasis on the strategic importance of the relational rather than the technical assets of the firm. It intimates that firms operate in a social context inside and outside their organizations and that these social interactions influence organizational innovation and its outcomes, particularly in high technological ventures.

For this paper we adopt a definition of social capital similar to that offered by Nahapiet and Ghoshal (1998). According to Nahapiet and Ghoshal (1998), social capital can be defined as "the accumulation of the actual and potential resources embedded within, available through, and derived from the network of relationships possessed by an individual or social unit." And they identify three dimensions of social capital, namely, structural, relational, and cognitive dimensions. Moreover, dimensions of social capital match with elements of knowledge transfer, that is, opportunity, will and capacity(Fig. 1). Structural dimension illustrates ties among individuals, which determines opportunity in knowledge transfer. Trust in relational dimension is critical to social exchange, which can affect actor's will to transmit information. Standing for common goal and share vision, cognitive dimension governs capacity in knowledge transfer.

\section{Comparisons of Conditions Facilitating Knowledge Transfer among Different Network}

Member firms acquire valuable diverse knowledge, and network become main conduit to transfer knowledge. Social capital plays important role in knowledge transfer in network. Based on above analysis, this research proposes the conditions facilitating knowledge transfer between firms embedded with social network (Tab. 1).

\section{A Structural Dimension}

1) Network ties

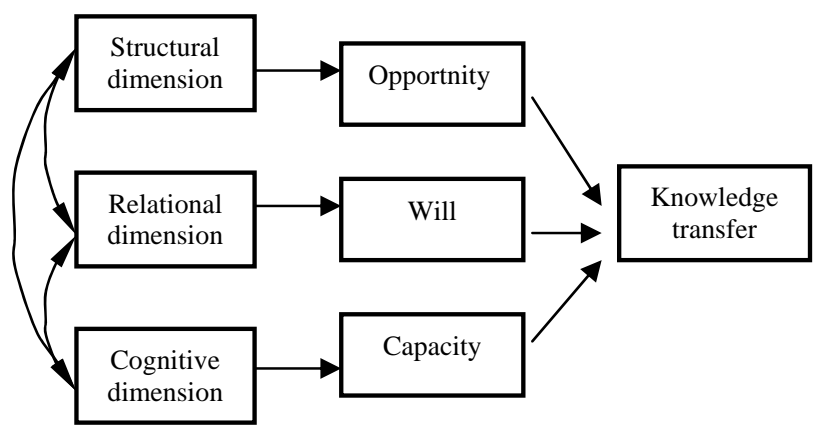

Figure 1. Match between dimension of social capital and knowledge transfer

Due to less psychological distance between MNC's subsidiaries, personnel communicate each other individually, which steps up social relation network.

In strategic alliance, maintaining strong ties with firm partners is essential to exchange knowledge effectly, especially, implicit knowledge hiding in strategic alliance. The elements to promote erecting strong ties include prior partner relationship and repeated transaction ${ }^{[10]}$. Jiang Chunyan(2006) also indicates strong ties help to accelerate trust and reciprocity $^{[13]}$.

For industrial clusters, Camagni (1995) ${ }^{[14]}$ identifies spatial proximity as a key characteristic of what he calls "a local network." It is beneficial for firms of cluster to maintain spatial proximity with other firms. The proximity helps the formation of network ties and interaction between firms and individuals in cluster, thus better effectiveness and efficiency of knowledge flow. And more implicitly knowledge is, more important spatial proximity each other.

\section{2) Network configuration}

Hierarchical structure in MNCs can be harmful to knowledge transfer, especially implicit knowledge, between subsidiaries ${ }^{[15]}$.Decentralizing authority to subsidiaries is effective conduit to alleviate hierarchy. Decentralization enables to fully utilize knowledge stock hold in subsidiaries and to share information among subsidiaries.

Succeeding knowledge transfer in strategic alliance should overcome obstruction of borders between firms. Inkpen and Dinur (1998) identify four types of alliance structural ties that can lead to knowledge sharing: technology linkages, alliance-parent interaction, personnel transfers, and strategic integration. The four types provide conduits for partners to reach knowledge and creativity out of alliance ${ }^{[10]}$. 
In industrial cluster, cliques of firms can be formed which characterize internal strong ties. For example, there are two cliques in manufacturing industry cluster in east of Shandong province, respectively be called, Korea clique and Japan clique. Although there is an intense knowledge exchanges within a clique, there is little between cliques.

\section{B Cognitive Dimension}

\section{1) Common goals}

According to opinion of network, share vision in MNC embodies collective goals and aspirations of subsidiaries ${ }^{[1]}$. Common value among subsidiaries enables to better understanding and resource exchange and sharing, and helps knowledge integration between subsidiaries.

In strategic alliance, alliance goal and strategy clarified explicitly can reduce conflict between partners, help to consult and negotiate about common goals, and promote knowledge transfer to share values and cooperation effect.
In industrial cluster, goals of firm characterize more diverse. Firms must recognize that congregation effect is formed through cooperation and knowledge sharing, and knowledge innovation is formed through integration of resources such as economic, cultural and technological resource. So, it is essential for knowledge sharing among firms to accelerate interaction and consistent values through personal relationship network.

\section{2)Shared culture}

Subsidiary of MNC is geographical embedded local cultural network. But culture of MNC may be incompatible with local host culture. Thus, unless MNC tolerates local host culture, cultural conflict would be an determinant to hinder knowledge transfer among subsidiaries.

There is not consistent standpoint about the influence on learning between firms from cultural diversity. Parkhe (1991) has proposed that diversity between the partners in international strategic alliances could lead to

Table 1. Comparison on conditions facilitating transfer knowledge

\begin{tabular}{|c|c|c|c|}
\hline $\begin{array}{l}\text { Social Capital } \\
\text { Dimensions }\end{array}$ & MNC & Strategic Alliance & Industrial Cluster \\
\hline \multicolumn{4}{|l|}{ Structural } \\
\hline Network ties & $\begin{array}{l}\text { Personal communication } \\
\text { between network members }\end{array}$ & $\begin{array}{l}\text { Strong tie through } \\
\text { repeated exchange }\end{array}$ & $\begin{array}{l}\begin{array}{l}\text { Geographic proximity } \\
\text { members }\end{array} \\
\end{array}$ \\
\hline $\begin{array}{l}\text { Network } \\
\text { configuration }\end{array}$ & $\begin{array}{l}\text { Decentralization of authority } \\
\text { by headquarters }\end{array}$ & $\begin{array}{lr}\text { Multiple } & \begin{array}{r}\text { knowledge } \\
\text { bonnections }\end{array} \\
\text { partners } & \\
\end{array}$ & $\begin{array}{l}\text { Weak ties and boundary spanners to } \\
\text { maintain relationships with various } \\
\text { cliques }\end{array}$ \\
\hline \multicolumn{4}{|l|}{ Cognitive } \\
\hline Common goals & $\begin{array}{l}\text { Shared vision and collective } \\
\text { goals }\end{array}$ & Goal clarity & $\begin{array}{l}\text { Interaction language derived from } \\
\text { cooperation }\end{array}$ \\
\hline Shared culture & $\begin{array}{l}\text { Accommodation for national } \\
\text { culture }\end{array}$ & Cultural diversity & $\begin{array}{l}\text { Norms and rules to govern informal } \\
\text { knowledge transaction }\end{array}$ \\
\hline \multicolumn{4}{|l|}{ Relational } \\
\hline Trust & $\begin{array}{l}\text { Clear and transparent incentive } \\
\text { mechanisms }\end{array}$ & Consideration of future & $\begin{array}{l}\text { Business transaction embedded social } \\
\text { relations }\end{array}$ \\
\hline
\end{tabular}

Modified from: (Inkpen and Tsang,2005)

learning $^{[16]}$. Thus, studies indicate that cultural diversity is beneficial for knowledge transfer.

In industrial cluster, there is a risk in informal knowledge exchange, that is, receptors do harm for knowledge senders. So, inherent norms and rules are claimed to govern informal knowledge transaction in cluster to reduce opportunism and risk.

\section{Relational Dimension}

The relational dimension of social capital focuses on trust as a key resource derived from relationships. Trust is related to an actor's belief that other partners are competent in performing their jobs. The MNC network is a social structure of coopetition ${ }^{[10]}$. Cooperation and competition are indispensable. Based on institutional trust, MNC should form clear and transparent incentive mechanisms to strengthen degree of trust between subsidiaries.

In strategic alliance, trust is based on action, which means firms improve to be trust through action. One partner cooperating long time, frequently interacting and transparently acting based on trust, then future of cooperation between partners seems very hopeful. The mechanism of trust enables to reduce anxiety about opportunism, reduce the barrier of spilling over of knowledge, and promote knowledge transfer.

In industrial cluster, the exchange among network members is commercial transaction, which is embedded with individual social relations. With interaction going, exchange of trust and reciprocity gradually infiltrates into future commercial transaction, which accelerates the process of unique knowledge transfer.

\section{Conclusions}

I believe that researchers must consider the potential conceptual differences across various network types. In this article I partially integrate three types of network and knowledge transfer among network members and provide a distinctive basis for comparing knowledge transfer determinants and conditions across different types of network. In the meanwhile, this article integrates organizational knowledge literature and three dimension of social capital (structural, relational and cognitive dimension). In order to 
transfer knowledge in effect, corporate must create and manage social capital. And this article also contributes to network literature, and conclusions can be validly extended to other type of network.

\section{References}

[1] Tsai W. Ghoshal S.. Social capital and value creation: The role of intra-firm networks[J]. Academy of Management Journal,1998, 41:464-476.

[2] Yu Peng. Study on knowledge transfer in MNC[D], ShanDong University, 2006.

[3] Wu Cuihua et al.. The effect on relational dimension of social capital to knowledge transfer in alliance network: an empirical study[J], Studies in Science of Science, 2008,(5).

[4] Zhang Zhiyong, Liu Yi, Tao Lei. Network and Knowledge Transfer:A Comparison Research on MNCs and Industrial District[J], Scientific Management Research, 2007,(4).

[5] Ghoshal S. Bartlett C.A..The Multinational Corporation as an Inter-organizational Network[J]. Academy of Management Review,1990, (15) :603 - 625.

[6] Gulati, R., Nohria, N. and Zaheer, A.. Strategic networks[J], Strategic Management Journal, 2000， 21: 203-215.

[7] Inkpen A.C., Dinur A. Knowledge management processes and international joint ventures[J]. Organization Science,1998, 9: 454-468.

[8] Hansen M.T.. Knowledge networks: Explaining effective knowledge sharing in multiunit companies[J] , Organization Science,2002,13:232-248.

[9] Gupta, A.K. and Govindarajan, V.. Knowledge flows within multinational corporations[J], Strategic Management Journal, 2000 , 21: 473-496.

[10] Inkpen A C. and Tsang E W K.,Social capital, network and knowledge transfer[J], Academy of Management Review, 2005, 30(1): 146-165.

[11] Wu Jiebing, Guo Bin. Coevolution of Firms' Adaptation, Networking and Industrial Cluster: a Longitudinal Study of Shaoxing County Textile Cluster[J], Management World, 2010,(2): 141-155.

[12] Nahapiet J. Ghoshal S. Social Capital, Intellectual Capital, and the Organizational Advantage[J]. Academy of Management Review,1998,23(2): 242-266.

[13] Jiang Chunyan. Breakthrough of Traps for Independent Innovation in Chinese New Ventures[J], China Industrial Economy, 2006,(10): 90-99.

[14] Camagni, R. 1995. Global network and local milieu: Towards a theory of economic space. In S. Conti, E. J. Malecki, and P. Oinas (Eds.), The industrial enterprise and its environment: Spatial perspectives: 195-214. Aldershot, UK: Avebury.

[15] Grant, R. M. Toward a knowledge-based theory of the firm[J]. Strategic Management Journal, 1996, 17: 109-122.

[16] Parkhe A. Interfirm diversity, organizational learning, and longevity in global strategic alliances[J]. Journal of International Business Studies,1991,22: 579-601. 